\title{
Rosario Ferré y la Generación del 70: Evolución estética y literaria
}

\author{
SANDra Palmer-López
}

East Tennessee State University

\section{T} La producción literaria de Rosario Ferré, junto a la de otros escritores y escritoras de su época, se cataloga, en la actualidad, bajo el título de la Generación del 70, que siguió la ideología política de los miembros de la Generación del 50. En "La figura en la alfombra: Nota sobre dos generaciones de narradores puertorriqueños", Efraín Barradas indica que las figuras principales de la Generación del 50 fueron José Luis González (1926), René Marqués (1919-1979), Pedro Juan Soto (1928) y Emilio Díaz Valcárcel $(1930)^{1}$. Barradas señala que los escritores de la Generación del 50 intentaron destruir en su obra la romantificación que de la isla y su cultura había llevado a cabo la generación literaria anterior ${ }^{2}$. Sobre la literatura puertorriqueña de la primera mitad del siglo XX, Luis O. Zayas señala que ésta mitifica la época decimonona, la isla y al jíbaro puertorriqueño en busca de reafirmación nacional, por lo cual Zayas la categoriza como una literatura de "tradición nativista y mitificante" ${ }^{3}$. Así vemos que, en oposición a este aspecto temático de la literatura de principios de siglo, González, Marqués, Soto y Valcárcel cuestionan y exponen en su obra el trauma social y político que sufre el pueblo puertorriqueño durante las décadas que van de $1940 \mathrm{a}$ 1960, época en que el país sufre una transformación política y sociocultural que, según la ideología de los escritores de la Generación del 50, contribuyó a "la angustia del puertorriqueño" colonial que aún rige al país. En "En torno a la nueva cuentística puertorri-

${ }^{1}$ Efraín Barradas, "La figura en la alfombra: Nota sobre dos generaciones de narradores puertorriqueños", Insula 356-57 (1976):5.

${ }^{2}$ Barradas 5.

${ }^{3}$ Luis O. Zayas, Mito y política en la literatura puertorriqueña (Madrid: Partenon, 1981).

${ }^{4}$ Barradas 5. 
queña”, Edna Acosta-Belén ofrece una descripción del contexto sociopolítico que les tocó vivir a los escritores de la Generación del 50:

A los escritores de la Generación del 50 les tocó enfrentarse a una época histórica de rápidas transformaciones sociales y políticas en el Puerto Rico de mediados de nuestro siglo -cambios provocados por el reformismo político y social del Partido Popular, la creación del Estado Libre Asociado, y la creciente anexión económica y agresión cultural norteamericanas"s.

Por esta razón, los textos literarios de la Generación del 50 encierran, según lo establecido por Acosta-Belén, una preocupación básica: "la vida del proletariado puertorriqueño en el ambiente urbano"6. Junto a esta precupación básica Acosta-Belén menciona otros temas: "La ruralía desplazada y agonizante, el mundo enajenante que surge con la industrialización y urbanización de la isla, la emigración masiva de los puertorriqueños a los Estados Unidos y el creciente poder asimilista de los Estados Unidos en Puerto Rico"7. Es decir, que básicamente la producción literaria de los miembros de la Generación del 50 es literatura comprometida social y políticamente. Aún así, la calidad artística de la obra de los escritores de la Generación del 50, especialmente la de René Marqués y José Emilio González, es indiscutible. Estos escritores no tan sólo llevaron a cabo una renovación temática, sino que también introdujeron "importantes innovaciones técnicas en la narrativa puertorriqueña, tales como el uso de la retrospección o 'flashback', el fluir de la conciencia y el monólogo interior, y las corrientes filosóficas del existencialismo y del absurdo"8.

Por otra parte, durante los años del 60 tuvieron lugar una serie de eventos históricos a nivel mundial que, junto a la realidad sociopolítica e histórica de Puerto Rico, contribuyeron a moldear la conciencia literaria de los jóvenes literatos de la Generación del 70, tales como la Revolución Cubana y su ideología socialista, las protestas en contra del reclutamiento militar obligatorio, la guerra de Vietnam, la denuncia de los hippies en contra de la injusticia social y de ideas arcaicas que dividen al género humano en jerarquías sociales, el resurgimiento del movimiento feminista y, en la literatura, la nueva revolución literaria hispanoamericana bautizada como el "Boom". Todos estos factores históricos, sociales y culturales contribuye-

${ }^{5}$ Edna Acosta-Belén, "En torno a la nueva cuentística puertorriqueña", Latin American Research Review 21.2 (1986):220.

${ }^{6}$ Acosta-Belén 221.

${ }^{7}$ Acosta-Belén 221.

${ }^{8}$ Acosta-Belén 221. 
ron, como ya hemos mencionado, en moldear la conciencia intelectual y literaria de los escritores de la nueva literatura puertorriqueña.

Zayas afirma que los integrantes de la Generación del 70 crecieron en los años de asimilación extranjerizante en Puerto Rico?. Según Zayas, desde la década de 1950 en adelante Puerto Rico comienza "la industrialización de la cultura”, creándose así un "extrañamiento del hombre puertorriqueño respecto de su mundo"10. Esta movilización industrial y asimilista se profundiza en el momento en que el Partido Popular -que defiende el estatus político del Estado Libre Asociado- pierde, por primera vez, las elecciones en 1967 y el gobernador que estuvo en el poder por veinticinco años, Luis Muñoz Marín, cede su posición política a Luis A. Ferré. Zayas señala que “en 1971 Luis A. Ferré, gobernador, dice que Puerto Rico es la patria y Estados Unidos es la nación y que por ello hay que sentir como puertorriqueños y pensar como norteamericanos" ${ }^{11}$. Esta dualidad, "sentir como puertorriqueños" y "pensar como norteamericanos", es decir, la fragmentación de la identidad del pueblo puertorriqueño, es una de las preocupaciones de los nuevos escritores de la Generación del 70. En sus textos literarios, los integrantes de la nueva literatura puertorriqueña intentan afianzar la identidad nacional, glorificando los sectores y habla populares. Esto los lleva, al igual que a los escritores de la Generación del 50, a la desmitificación del idilio de los escritores de la primera mitad del siglo XX, quienes buscaban la reafirmación de la identidad nacional en el pasado decimonono, el pasado mítico de la época de las haciendas de café y de caña de azúcar, de la economía agrícola de Puerto Rico anterior al cambio de soberanía en $1898^{12}$. Haciendo eco a las ideas de Zayes podemos asegurar que la Generación del 70 es la generación de la destrucción de mitos arcaicos tanto literarios como sociales ${ }^{13}$.

${ }^{9}$ Zayas 188.

${ }^{10}$ Zayas 188.

${ }^{11}$ Zayas 189.

${ }^{12}$ Rosario Ferré parodia las novelas de la tierra y el mito de la época de las haciendas de fines del siglo XIX en su novela corta Maldito amor.

${ }^{13}$ Zayas 188-89. "Los escritores de los sesenta que nos acompañan presentan un mundo de profanación de lo sagrado, arte de lo común, de lo homogéneo... Es la muerte del mito.... Para el político todo está bien. Para los hombres de conciencia es un infierno. Por ello vemos que Luis Rafael Sánchez, Carmelo Rodríguez Torres y Rosario Ferré, hija del gobernador, trasuntan mundos infernales, pero vistos como paraísos". 
En "Narradores puertorriqueños", José Alcántara Almanzar categoriza a esta nueva generación literaria como "expresión de desafío abierto al apabullante colonialismo y defensa de los más auténticos valores de la cultura boricua", añadiendo que "el escritor puertorriqueño es ante todo un lúcido testigo de su tiempo, un hacedor de mundos particulares que no da la espalda a la sociedad sino que va hacia ella para tomar del conjunto lo que más le interesa o le impone su sensibilidad" ${ }^{14}$. En cuanto al rasgo principal de la nueva literatura puertorriqueña, Alcántara Almanzar afirma que es la "autenticidad", puesto que en esta literatura "se mezclan el testimonio, la crítica y la denuncia sociales con formulaciones subjetivas y oníricas"15.

En "Nota" Barradas señala que los aires precursores de la nueva generación literaria comenzaron a sentirse en el año de 1966 con la publicación de la colección de cuentos En cuerpo de camisa de Luis Rafael Sánchez, colección que es seguida en 1971 por otras producciones literarias: Concierto de metal para un recuerdo de Manuel Ramos Otero (1950); Cordial magia enemiga de Tomás López Ramírez (1946), y Veinte siglos después del homicidio de Carmelo Rodríguez Torres $(1941)^{16}$. Aun en este momento precursor, Barradas toma conciencia de que uno de los rasgos más distintivos de la joven generación literaria que la distingue de la Generación del 50 es el "barroquismo lingüístico y su arraigo en lo camp de nuestra cultura popular" y añade que "la nueva generación busca soluciones más imaginativas y fantásticas", aunque ambas generaciones literarias -la del 50 y del 70- se aúnan por intentar "esclarecer la problemática del hombre puertorriqueño" ${ }^{17}$ : su identidad cultural.

Barradas reunió finalmente a los escritores de la Generación del 70 en la antología titulada Apalabramiento: Cuentos puertorriqueños de hoy ${ }^{18}$, generación de la cual sobresalen Rosario Ferré y Luis Rafael Sánchez, precursor y máximo exponente ${ }^{19}$. En la introducción a Apalabramiento Efraín Barradas

${ }^{14} J$ José Alcántara Almanzar, “Narradores puertorriqueños”, ;Ahora! 895 (1981):41.

${ }^{15}$ Alcántara Almanzar 41.

${ }^{16}$ Barradas 5.

${ }^{17}$ Barradas 5.

${ }^{18}$ Efraín Barradas, ed., Apalabramiento: Cuentos puertorriqueños de hoy (New Hampshire: Norte, 1983). Barradas tomó el título de su antología de Cuentos puertorriqueños de hoy (Puerto Rico: Cultural, 1975) editada por René Marqués. La antología de Marqués contiene selecciones narrativas de los miembros principales de la Generación del 50: Abelardo Díaz Alfaro, José Luis González, René Marqués, Pedro Juan Soto, Edwin Figueroa, José Luis Vivas, Emilio Díaz Valcárcel, Salvador M. de Jesús.

${ }^{19}$ Angel Rama, "Luis Rafael Sánchez y Rosario Ferré: Dos narradores puertorriqueños", El Universal [Caracas], 19 febrero 1978: 1-2. Angel Rama señala que tanto 
señala que la cuentística de la nueva generación de escritores puertorriqueños se caracteriza por varios aspectos: por la experimentación con el lenguaje popular, rechazando las normas estéticas y lingüísticas; por un acercamiento general a los sectores marginados de la sociedad nacional, atacando a la clase media; por una identificación con el mundo latinoamericano y caribeño, y por una destacada perspectiva feminista en un esfuerzo constante por erradicar el machismo en nuestra sociedad ${ }^{20}$. Barradas hace la observación de que "[n]o todos los cuentistas de este grupo comparten [los mismos] rasgos aunque, en mayor o menor medida, varios de éstos aparecen en sus obras", estableciendo, sin embargo, que el rasgo común que los une es "su apalabramiento"21. Sobre el apalabramiento de la Generación del 70 como rasgo unificador de los textos literarios de la Generación del 70, Barradas señala en "Estado de cuentas" que es "el interés y la lucha de sus autores por crear un lenguaje literario nuevo y propio", además de que "todos están conscientes de la necesidad de ir creando una nueva lengua literaria que responda a la realidad social que vivimos" a fin de que "sirva para remediar [todos] los males sociales que afligen a nuestro pueblo"22. En "En torno a la nueva cuentística puertorriqueña", Acosta-Belén se aúna con Barradas para destacar que el uso novedoso del lenguaje es uno de los rasgos más sobresalientes de la nueva literatura puertorriqueña ${ }^{23}$.

Sánchez como Ferré han logrado trascender las barreras geográficas del país para integrarse al resto de la literatura latinoamericana.

${ }^{20}$ Barradas, Apalabramiento xvii-xxvii. Al final de su ensayo, Barradas ofrece un resumen de los rasgos distintivos de la obra narrativa de los miembros de la Generación del 70: "Se destacan estas narraciones por la fusión de su voz narrativa y voz de los personajes; por su fascinación por lo histórico entendido en términos estéticos; por la nueva identidad que en ellos se establece con el proletariado puertorriqueño, con el mundo antillano y con el resto de América Latina; por el empleo del lenguaje de las clases económicamente bajas como base para la creación de una lengua literaria propia; por la presentación indirecta de la decadencia de la clase media de raíces decimonónicas; por su aporte de un punto de vista femenino y feminista; por su conciencia de la literatura del texto mismo".

${ }^{21}$ Barradas, Apalabramiento xxvii. "No todos los cuentistas de este grupo comparten [los mismos] rasgos aunque, en mayor o menor medida, varios de éstos aparecen en sus obras. Pero, ¿hay algo que los una a todos?... Creo posible postular correctamente la existencia de tal rasgo común: su apalabramiento".

${ }^{22}$ Efraín Barradas, "Estado de cuentas", Claridad Suplemento En Rojo [Puerto Rico], 21 junio 1979:8.

${ }^{23}$ Acosta-Belén 220-21señala: "La narrativa puertorriqueña de hoy nos habla en otra lengua, un lenguaje que a pesar de estar enraizado en las modalidades dialectales y en la cultura popular puertorriqueñas trasciende el tradicional calco lingüístico de 
Zayas afirma también que la "profanación más grande y auténtica" llevada a cabo por Luis Rafael Sánchez y por todos los integrantes de la Generación del 70, "es la del lenguaje"24. Según Zayas, éste es un lenguaje literario que " $[\mathrm{r}]$ ompe con todo el pasado lingüístico hasta hacer añicos cuantos dogmas y normas establecidos" 25 . Aun cuando el lenguaje novedoso apalabramiento- distingue el contexto literario de esta generación, hay otro aspecto que la cataloga como única hasta ese momento en el desarrollo de la literatura puertorriqueña: el aporte de un grupo de escritoras destacadas como nunca antes en el género narrativo. Barradas y Acosta-Belén señalan que éste es el rasgo más distintivo de la Generación del 70 que la distingue ampliamente de la Generación del 50. Barradas señala que "es imposible descartar y, menos aún, ignorar, la corriente femenina-feminista en nuestro cuento" 26 . Esta "corriente femenina-feminista" la componen, entre otras, Rosario Ferré, Magali García Ramis, Carmen Lugo Filipi, Mayra Montero y Ana Lydia Vega, quienes, según Barradas, se interesan por primera vez en la cuentística puertorriqueña en "utilizar incidentes de la vida de la mujer boricua de distintas clases sociales para denunciar a través de sus cuentos la opresión machista que sufre la mujer en nuestra cultura" ${ }^{27}$. Acosta-Belén re-afirma, desde una perspectiva feminista, que la presencia femenina en nuestras letras "no es solamente un grito de nuestros tiempos, es prueba fehaciente de que la mujer escritora, que por muchos años se había dedicado al ejercicio poético, al fin ha logrado lanzarse al mundo de la ficción logrando méritos que no pueden ser ignorados por ningún estudioso" ${ }^{28}$. Sin embargo, a pesar de la diferencia temática y lingüística, los escritores de las generaciones del 50 y del 70 se entrelazan ideológicamente: todos están conscientes de la realidad social, política y cultural del Puerto Rico que les ha tocado vivir. Al igual que la producción literaria de los escritores de la Generación del 50, los escritores de la Generación del 70 se preocupan por definir la identidad cultural de Puerto Rico y, además, por denunciar el deterioro asimilista de la clase burguesa. Así vemos que la literatura puertorriqueña, al igual que la literatura latinoamericana, ha mostrado siempre un carácter político. El escritor puertorriqueño, al igual que el latinoamericano, vive consciente del acontecer político-social del país y presenta esa preocupación en su tex-

la 'manera de hablar' de los personajes y se convierte en instrumento versátil, metafórico y paródico del narrador".

${ }^{24}$ Zayas 162 .

${ }^{25}$ Zayas 162.

${ }^{26}$ Barradas, Apalabramiento xix.

${ }^{27}$ Barradas, Apalabramiento xix.

${ }^{28}$ Acosta-Belén 226. 
to literario. La literatura de la Generación del 70 continúa estas pautas, pero añade otros temas, también de índole política: el conflicto de clases y la situación sojuzgada de la mujer en una sociedad patriarcal.

Todos estos elementos van cogidos de la mano en la obra de Rosario Ferréé $^{29}$, especialmente en su primer libro, Papeles de Pandora (1976), en el cual, según Alcántara Almanzar, "explora todo un universo social deformado por el colonialismo, incursionando en la vida de la clase dominante, poniendo al desnudo sus perversiones y progresiva extranjerización" ${ }^{30}$. Alcántara Almanzar señala, además, que Rosario Ferré es una "figura importante de la nueva literatura puertorriqueña" 31 . Aunque la obra de Ferré no refleja la misma temática sociopolítica de los escritores de la Generación del 50, sí refleja una denuncia sociopolítica en contra de la decadente burguesía puertorriqueña ${ }^{32}$ colonizada política y psicológicamente. En 1972 Ferré fundó y dirigió una de las revistas crítico-literarias más importantes de Puerto Rico y de América Latina, Zona de Carga y Descarga (1972-1975), "especializada en la difusión de la nueva literatura puertorriquena" ${ }^{33}$. En "Las revistas literarias: Poesía, política, cultura”, Rubén González señala que “[d]e las revistas literarias publicadas en los años 60 y principios de la década del 70, Zona de Carga y Descarga se mostró como la más abundante en perspectivas, la que desplazaba un mayor dominio sobre el terreno literario puertorriqueño" ${ }^{34}$. En su artículo González menciona que uno de los obje-

${ }^{29}$ Rosario Ferré nació en 1942 en Ponce, ciudad de gran prosperidad económica y cultural al sur de Puerto Rico, en el seno de una de las familias más influyentes económica y políticamente del país. Sus primeros años se desarrollaron según "la vida típica de una joven de su clase hasta finales de los años 60, cuando cursa estudios postgraduados en la Universidad de Puerto Rico". Su padre, Luis A. Ferré, fue uno de los gobernadores de la isla durante el cuatrienio de 1968-1972 por el Partido Nuevo Progresista, de ideología anexionista. Durante esta época, Rosario Ferré militó en las filas del Partido Independentista Puertorriqueño, haciendo pública su posición en cuanto al estatus político de Puerto Rico, posición política que confligía abiertamente con la posición anexionista de don Luis. Durante estos años, Rosario Ferré atrajo bastante crítica social por su posición en cuanto al estatus político de Puerto Rico, por su posición feminista y por su censura literaria en contra de la clase social a la cual pertenecía: la clase burguesa puertorriqueña.

${ }^{30}$ Alcántar Almanzar 41.

${ }^{31}$ Alcántara Almazar 41.

${ }^{32}$ Barradas, Apalabramiento xxi.

${ }^{33}$ Lisa E. Davis, "La puertorriqueña dócil y rebelde en los cuentos de Rosario Ferré", Sin Nombre 9 (1980):83.

${ }^{34}$ Rubén González, "Las revistas literarias: Poesía, política, cultura", Revista de Estudios Hispánicos 13 (1986):103. 
tivos principales de los editores de Zona... fue la preocupación por crear un diálogo entre estudiantes, profesores, escritores y críticos literarios a fin de llevar "a la toma de conciencia tanto de nuestra realidad social como de nuestra realidad literaria" ${ }^{35}$. Los jóvenes editores ${ }^{36}$ de Zona... insistían en la necesidad de una crítica literaria puertorriqueña que contribuyera en la continuidad de la producción literaria: "[e]s imposible que haya continuidad si no existe el diálogo entre el creador profesional y el crítico", a fin de que a través de éste se pueda "modular la visión compleja de nuestra realidad" ${ }^{37}$. Señala González que estas críticas a la crítica literaria puertorriqueña suponían y exigían una "revisión de la literatura, un intento de comprensión de la evolución literaria" puertorriqueña ${ }^{38}$. Otro objetivo de Zona... fue el de "determinar la función de la literatura, de la producción cultural como significante en la reorganización de la sociedad" 39 . Es decir, la literatura debía cumplir una función sociopolítica de denuncia y contribuir en la promoción del sentido de identidad nacional y cultural, pero cuidándose de no caer en la "panfletería de fácil compromiso que descuida la forma" ${ }^{40}$. Zona de Carga y Descarga contribuyó también en la discusión y difusión de temas feministas "a favor de la liberación femenina" "11 que en la década de 1970 comenzaba a cristalizarse nuevamente, siendo sobre todo vehículo de expresión en contra de los "tabúes sexuales y religiosos" ${ }^{42}$. Este doble enfoque político se refleja en la obra literaria de Rosario Ferré: la preocupación por la identidad nacional y la situación sociopolítica de la mujer.

Rosario Ferré es una escritora que goza de una amplia educación literaria e intelectual y esto se proyecta en el uso de la intertextualidad en su obra. Elsa R. Arroyo asegura que "[l]os textos de Ferré exigen un lector culto, informado y entrenado en la lectura de textos literarios" y añade que Ferré "se vale de recursos ampliamente desarrollados y experimentados por

${ }^{35}$ Editorial Zona de Carga y Descarga 3 (1973). Citado por R. González 103.

${ }^{36}$ Rubén González menciona a Rosario Ferré en la directiva y a Olga Nolla, Luis César Rivera, Waldo C. Lloreda, Eduardo Forasteri en el comité de redacción. Zona de Carga y Descarga tuvo la colaboración de varias figuras literarias hispanoamericanas de renombre, tales como José Luis González, Severo Sarduy, Mario Vargas Llosa, Luis Rafael Sánchez, José Donoso y Lezama Lima, entre otros.

${ }^{37}$ Editorial, Zona de Carga y Descarga 1 (1972). Citado por R. González 103.

${ }^{38} \mathrm{R}$. González 104.

${ }^{39} \mathrm{R}$. González 105.

${ }^{40} \mathrm{R}$. González 106.

${ }^{41} \mathrm{R}$. González 106.

${ }^{42} \mathrm{R}$. González 106. 
la tradición literaria occidental", tales como "técnicas surrealistas" y el "uso de alusiones cultas clásicas y de un cargado lenguaje barroco" ${ }^{43}$. Desde pequeña, Ferré leía con avidez libros de literatura y los cuentos de hadas ${ }^{44}$ de los hermanos Jacob y Wilhelm Grimm, de William A. Hoffman y de Hans Christian Andersen, género literario que influye profundamente en su obra literaria. Comenzó a escribir poemas a temprana edad y en su juventud publicó varios artículos en el periódico El Día de Puerto Rico ${ }^{45}$. Cursó estudios de bachillerato en literatura inglesa y francesa en Manhattanville College en los Estados Unidos. Obtuvo el título de maestría con especialización en literatura latinoamericana de la Universidad de Puerto Rico en 1982 y el título de doctorado de la Universidad de Maryland en 1987 con una disertación sobre los cuentos de Julio Cortázar ${ }^{46}$, publicada en 1999 bajo el título Cortázar: El romántico en su observatorio ${ }^{47}$. Durante los años de maestría tuvo como profesores a varios escritores y críticos literarios de renombre, tales como el escritor Mario Vargas Llosa, el crítico literario Angel Rama y la profesora y crítica literaria puertorriqueña Margot de Arce, personalidades que influyeron en su vocación literaria. Por otro lado, el crítico e historiador de literatura puertorriqueña Francisco Manrique Cabrera fue figura influyente en el desarrollo de su compromiso sociopolítico ${ }^{48}$.

En 1976 los cuentos $^{49}$ de Rosario Ferré fueron premiados por el Ateneo Puertorriqueño ${ }^{50}$ y desde la década de 1980 su obra literaria ha sido publicada en diferentes revistas literarias y antologías de Puerto Rico, de Latino-

${ }^{43}$ Elsa R. Arroyo, "La contracultura, la parodia y lo grotesco: Carnavalización de la literatura en los cuentos de Rosario Ferré y Ana Lydia Vega”, diss., S U New Jersey, 1989, 39.

${ }^{44}$ Rosario Ferré, "El cuento de hadas", Sin Nombre 2 (1980): 36.

${ }^{45}$ Julia Gallardo Colón, Rosario Ferré, Biographical Dictionary of Hispanic Literature in the USA. Nicholas Kanellos ed. (Greenwood: Greenwood P., 1989): 100.

${ }^{46}$ Marie-Lise Gazarian Gautier, "Entrevista a Rosario Ferré", Interviews with Latin American Writers (Illinois: Palkey Archive, 1989): 81.

${ }^{47}$ Rosario Ferré, Cortázar: El romántico en su observatorio (Hato Rey, P. R.: Cultural, 1990).

${ }^{48}$ Gallardo Colón 100. "[Manrique Cabrera] unfolded in front of her a cyclical vision of Puerto Rican history and identity”.

${ }^{49}$ Los cuentos de Rosario Ferré aparecieron en las revistas Zona de Carga y Descarga y en $\operatorname{Sin}$ Nombre. Ferré recopiló sus cuentos y poemas narrativos en la colección de Papeles de Pandora (México: Mortiz, 1976).

${ }^{50} \mathrm{El}$ Ateneo Puertorriqueño es una institución cultural que fue establecida en 1864 . 
américa y de los Estados Unidos ${ }^{51}$. Su obra literaria de carácter ecléctico ${ }^{52}$, la cual comunica desde una perspectiva feminista e "histórica una visión crítica de la sociedad puertorriqueña" ${ }^{\text {"33 }}$, comprende hasta la fecha una colección de seis poemas narrativos y catorce cuentos, Papeles de Pandora (1976); una colección de cuentos infantiles de varios temas, tales como cuentos de hadas desarrollados desde una perspectiva feminista ${ }^{54}$, El medio pollito (1978), folklóricos y picarescos, Los cuentos de Juan Bobo (1980) y La mona que le pisaron la cola (1981), recopilados en la colección de cuentos Sonatinas (1989); una colección de ensayos biográficos sobre mujeres que destruyeron el mito del eterno femenino a través de su vida y obra, Sitio a Eros (1980); una colección de poemas y narrativa sobre figuras femeninas mitológicas, literarias e históricas, Fábulas de la garza desangrada (1982); una novela corta, "Maldito amor", publicada con tres cuentos en la colección titulada Maldito amor (1985); una colección de ensayos, El árbol y sus sombras (1989); un libro de crítica literaria, El coloquio de las perras (1990); una colección de poemas y cuentos, Las dos Venecias (1992); una novela, La batalla de las vírgenes (1993); una serie de ensayos de crítica literaria sobre diversos temas y autores, los cuales han aparecido en diferentes revistas literarias y periódicos ${ }^{55}$; una colección de poemas en gestación

${ }^{51}$ Julia Gallardo Colón señala que selecciones de la producción literaria de Rosario Ferré han aparecido en varias revistas literarias, tales como Zona de Carga y Descarga, Sin Nombre, Vórtice, Novedades, Repertorio Latinoamericano, Escritura, Revista de la Universidad de México y Kenyon Review y en varias antologías, tales como, Novísimos narradores en marcha 1964-1980, ed. de Angel Rama, y Apalabramiento, ed. de Efraín Barradas.

${ }^{52}$ Miguel Angel Zapata, Entrevista, "Rosario Ferré: La poesía de narrar", Inti: Revista de Literatura Hispánica, 26-27 (1987-88):133. En esta entrevista Rosario Ferré define su producción literaria como "extensamente variada, para no decir ecléctica...”.

${ }^{53}$ Raquel Chang-Rodríguez y Malva E. Filer, eds., Introducción biográfica de Rosario Ferré, Voces de Hispanoamérica: Antología literaria (Boston: Heinle, 1987): 519-20.

${ }^{54} L u z$ María Umpierre-Herrera, "Los cuentos ¿infantiles? de Rosario Ferré: estrategias subversivas”, Nuevas aproximaciones criticas a la literatura puertorriqueña contemporánea (Puerto Rico: Cultural, 1983): 92.

${ }^{55}$ A continuación ofrecemos referencia bibliográfica de algunos de los ensayos críticos de Rosario Ferré: "Oppiano Licario, o la resurrección por la imagen”, Escritura 2 (1976): 319-26; "El cuento de hadas", Conferencia dictada en el Colegio Universitario del Turabo, Caguas, Puerto Rico, 25 abril 1980; "El cuento de hadas", Sin Nombre 11:2 (1980): 3-40; "La cocina de la escritura", Literatures in Transition: The Many Voices of the Caribbean Area: A Symposium, ed. Rose S. Minc (Gaithersburg: Hispamérica, 1982): 37-51; "S/Z, una pregunta que responde y una respuesta que pregunta", Texto Crítico 30 (1984): 7-12; "Entre Clara y Julia: Dos poetas puertorriqueñas", Revista Iberoamericana 52:137 (1986): 999-1.006; "Desnuda está, brilla la 
que llevará el título El eco de las sombras ${ }^{56}$ y una novela publicada en inglés The House on the Lagoon (1995) y en español, La casa en la laguna. Aunque la producción literaria de Rosario Ferré se ramifica a través de diversos géneros literarios, su interés primario radica en el género narrativo del cuento ${ }^{57}$.

Debido al rápido reconocimiento en los Estados Unidos de la obra literaria de Rosario Ferré, varios de sus textos han sido traducidos al inglés: algunos de los cuentos de la colección de Papeles de Pandora: "When Women Love Men" ("Cuando las mujeres quieren a los hombres"), "The Youngest Doll” ("La muñeca menor"), "Sleeping Beauty" ("La bella durmiente") y la colección completa bajo el título The Youngest Doll; la colección de la novela Sweet Diamond Dust (Maldito amor); el cuento intantil "Pico Rico, Mandorico", y el ensayo "The Write's Kitchen" ("La cocina de la escritura" ${ }^{58}$. El cuento "La muñeca menor", que introduce la colección de Papeles

estrella", Third Woman 3:1-2 (1986): 81-85; "Vargas Llosa o el escribidor", Sin Nombre 9:ii (1986): 86-90; "Felisberto Hernández: La vanguardia de un hombre solo", La Gaceta del Fondo de Cultura Económica 185 (1986): 17-19.

${ }^{56}$ Zapata 136.

${ }^{57}$ Zapata 133-34. En la entrevista con Miguel Angel Zapata, Rosario Ferré señala que se considera "fundamentalmente cuentista". Y añade: "Me gusta, ante todo, contar, y de mi vida se puede decir con razón que he vivivido el 'cuento'. En Puerto Rico 'vivir el cuento' significa no trabajar, ser un parásito de la sociedad, y esto es cierto, ya que el artista es necesariamente un parásito social, pero también por ello es víctima de la sociedad. Los artistas vivimos de representar aquello por lo cual somos luego sacrificados, ya que la sociedad no perdona a quienes les muestran sus defectos, a pesar de necesitarnos para sobrevivir. En realidad todas mis obras son cuentos: mis poemas son cuentos en verso, mi novela Maldito amor son cuatro novelas cortas o cuentos largos unidos por varios temas, mis ensayos tienen siempre un hilo narrativo que resulta más interesante que el análisis técnico, etc. Me gusta llamarme a mí misma 'cuentista' en lugar de escritora precisamente porque el término es andrógino. Da igual ser la 'cuentista'que el 'cuentista' pero no la 'escritora' o el 'escritor'... Entre 'cuentista' y cuentista'... no hay diferencias ni incompatibilidades porque ambos viven, se nutren, del gozo de contar".

${ }^{58}$ Rosario Ferré, The Youngest Doll, trad. Rosario Ferré (Río Piedras, P. R.: Huracán, 1979; "The Youngest Doll," trad. Gregory Rabassa, Kenyon Review 2:1 (1980):163-67; Reclaiming Medusa: Short Stories by Contemporary Puerto Rican Women, ed. Diana Vélez, trad. Diana Vélez y Rosario Ferré (San Francisco: Spinster/Aunt Lute, 1988) 27-22; Longman Anthology of World Literature by Women: 1887-1975, eds. Marian Arkin y Barbara Shollar (New York: Longman, 1989): 1.055-1.058; "When Women Love Men", trad. Cynthia Ventura, Contemporary Women Authors of Latin America: Introductory Essays in Translation, eds. Doris Meyer y Margarite Fernández Olmos (Brooklyn: Brooklyn CP, 1983). "The Writer's Kitchen”, trad. Diana L. Vélez, Feminist Studies 12:2 (1986): 227-42. "El abrigo de zorro azul/The Fox Skin Coat", trad. Rosario Ferré, Mester 15.2 (1986): 699-71. "Pico Rico, Mandorico", Reclaiming Medusa: Short Stories by Contemporary Puerto Rican Women, ed. y trad. Diana Vélez (San Francisco: Spinster/Aunt Lute, 1988): 
de Pandora, ha sido publicado en la antología Voces de Hispanoamérica y la novela corta "La bella durmiente" de Papeles... ha sido publicada en la antología Ritos de iniciación ${ }^{59}$. Hasta ahora la crítica se ha desvelado en el análisis feminista de su primer libro, Papeles de Pandora (1976). Los comentarios crítico-literarios sobre esta colección de cuentos y poemas han aparecido en tres disertaciones ${ }^{60} \mathrm{y}$ en varios artículos publicados en diversas revistas literarias ${ }^{61}$. Asimismo, se han publicado comentarios críticos sobre Sitio a Eros (1980), Fábulas de la garza desangrada (1982) y de los cuentos "infantiles" 62.

La obra de Rosario Ferré representa, por lo tanto, un nuevo giro en el devenir histórico de la literatura puertorriqueña, no tan sólo por romper con la tradición del género femenino por excelencia, la poesía ${ }^{63}$, sino por la

64-72. "Sleepig Beauty," Reclaiming Medusa, ed. Diana Vélez, trad. Diana Vélez y Rosario Ferré (San Francisco: Spinster/Aunt Lute, 1988): 34-63. Sweet Diamond Dust, trad. Rosario Ferré (New York: Ballantine P., 1988).

${ }^{59}$ Chang-Rodríguez y Filler 520-27. Grínor Rojo y Cynthia Steele, eds., Ritos de iniciación (Boston: Houghton, 1986): 147-213.

${ }^{60}$ Elsa R. Arroyo, "La contracultura, la parodia y lo grotesco: Carnavalización de la literatura en los cuentos de Rosario Ferré y Ana Lydia Vega", diss. S U of New Jersey, 1989. Antonia García-Rodríguez, "Female Feelings of fragmentation in Rosario Ferrés Papeles de Pandora and Elena Poniatowska's Hasta no verte Jesús mío", diss. S U of New York, 1988. Ivette López Jiménez, "Escritoras puertorriqueñas del 70: Nuevos caminos", diss. Yale U, 1978.

${ }^{61}$ A continuación ofrecemos, por orden de publicación, varios artículos de análisis crítico sobre Papeles de Pandora: Luz María Umpierre, "Un manifiesto literario: Papeles de Pandora de Rosario Ferré", The Bilingual Review: La Revista Bilingüe 9 (1982): 120-26. Yvette López Jiménez, “La muñeca menor’: Ceremonias y transformaciones en un cuento de Rosario Ferré”, Explicación de Textos Literarios 11.1 (1982-83): 49-58. María José Chávez, "La alegoría como método en los cuentos y ensayos de Rosario Ferré", Third Woman 2.2 (1984): 64-76. Margarita Fernández-Olmos, "Desde una perspectiva femenina: La cuentística de Rosario Ferré y Ana Lydia Vega”, Homines 8.2 (198485): 303-11. Lucía Guerra-Cunningham, "Tensiones paradójicas de la femineidad en la narrativa de Rosario Ferré", Chasqui 13.2-3 (1984): 13-25. María Inés Lagos-Pope, "Sumisión y rebeldía: El doble o la representación de la alienación femenina en narraciones de Marta Brunet y Rosario Ferré”, Revista Iberoamericana 51 (1985): 731-49.

${ }^{62}$ Margarite Fernández-Olmos, "Constructing Heroines: Rosario Ferré's 'Cuentos infantiles' and Feminine Instruments of Change”, The Lion and the Unicorn 10 (1986): 83-94; "Los cuentos infantiles de Rosario Ferré o la fantasía emancipadora", Revista Crítica Literaria Latinoamericana 14.7 (1988):151-63. Juan Gelpi-Pérez, "Especulación, especularidad y remotivación en Fábulas de la garza desangrada de Rosario Ferré", La Chispa: Selected Proceedings, ed. Gilbert Paolini (New Orleans: Tulane U, 1985): 125-32.

${ }^{63}$ María José Chaves, "La alegoría como método en los cuentos y ensayos de Rosario Ferré", Third Woman 2.2 (1984): 64. 
doble posición política que adopta en cuanto a la defensa de la mujer en la sociedad patriarcal y la problemática de indentidad nacional. Podemos afirmar, entonces, que el enfoque temático de la obra de Rosario Ferré se polariza, básicamente, a través de dos vertientes políticas: exponer la situación sociopolítica de la mujer en la sociedad patriarcal y ofrecer la mujer puertorriqueña como alegoría de la situación política de la isla de Puerto Rico. Tampoco podemos olvidar que el lenguaje de la obra literaria de Rosario Ferré sirve dos funciones políticas desde una perspectiva feminista: cuestionar el canon literario sobre el lenguaje adecuado de la escritora y cuestionar el mito patriarcal del eterno femenino que codifica el habla femenina en general. La obra de Ferré es comprometida, puesto que cuestiona la superficialidad de la clase burguesa puertorriqueña que contribuye tanto en la asimilación norteamericana como en la prolongación de ideas arcaicas que promueven la sojuzgación social de la mujer ${ }^{64}$. En la producción literaria de Ferré se refleja la teoría feminista de la re-visión crítico-literaria, según los postulados de la poeta norteamericana Adrienne Rich. Por ejemplo, en las colecciones de ensayos crítico-literarios, Sitio a Eros (1980) y El coloquio de las perras (1990), Ferré cuestiona varios mitos patriarcales sobre la esencia femenina: el mito de la incapacidad intelectual y literaria de la mujer y el mito del amor como su única temática y finalidad en la vida. Otro aspecto que Ferré cuestiona, especialmente en el ensayo "El coloquio de las perras", es la imagen equívoca de la mujer en la literatura masculina y el enfoque sexista del canon literario. Estas obras ferrerianas son una alternativa a la literatura tradicional masculina y en ellas encontramos, sintetizada, la ideología feminista y literaria de Rosario Ferré.

Como hemos podido observar, la obra literaria de Rosario Ferré se polariza, hasta la fecha, a través de varios géneros literarios: la novela, la novela corta, el cuento, los poemas narrativos y el ensayo de crítica literaria. Su posición dentro del ámbito literario se bifurca a través de dos ramas opuestas: crítica literaria y escritora de ficción. Sobre la contribución y posición histórico-literaria de la producción literaria de Rosario Ferré, Julia Gallardo Colón señala: "Her noteworthy literary creation, her experimentation with language and with universal literary trends to re-create in her fiction the Puerto Rican historical environment, while projecting a strong Antillean voice, assures Rosario Ferré a place at the vanguard of Hispanic American Literature $^{65}$.

\footnotetext{
${ }^{64}$ Alcántara Almanzar 41-42.

${ }^{65}$ Gallardo Colón 99.
} 